\title{
EL JOVEN NERUDA: \\ LOS POEMAS DEL AMOR COMPARTIDO
}

POR

JoRGE EDWARDS

En el Santiago de 1921, en una pensión de la calle Maruri, situada en los barrios del poniente, al otro lado de la Cordillera de los Andes, un joven provinciano de diecisiete años de edad escribía dos, tres, hasta cinco poemas al día. Su nombre civil era Neftalí Ricardo Reyes Basoalto, pero él ya había decidido adoptar e imponer a los demás el seudónimo de Pablo Neruda. Era una manera de liberarse del ambiente de la familia, dominado por un padre hostil a su vocación literaria; era un reconocimiento de sus constantes lecturas de narradores eslavos, y era además, un homenaje al checo Jan Neruda, autor de notables Cuentos de la Mala Strana.

En los atardeceres, como contó muchos años más tarde, el joven Neruda salía religiosamente al balcón y contemplaba el extraordinario espectáculo del crepúsculo: grandiosos hacinamientos de colores, repartos de luz, abanicos inmensos de anaranjado y escarlata. Así terminó su primer libro de poemas, reunido al comienzo en un cuaderno que llevaba el título de Helios antes de cuajar en el inconfundible Crepusculario. El joven que había crecido en Temuco, en tierras de frontera con la antigua Araucanía, y que estudiaba la asignatura de francés en el Instituto Pedagógico de Santiago, revelaba ya con ese neologismo el espíritu enumerativo, coleccionista, que desarrollaría en gran escala en su vida y en su poesía madura: recopilador de crepúsculos, de odas, de extravagancias, de amores, de epopeyas.

Crepusculario fue editado en Santiago en 1923. Era la obra de un epígono del modernismo hispanoamericano, pero ya se notaba de algún modo, en forma tímida, ingenua, un acento personal. Las imágenes del sur de Chile, de las tierras verdes y amarillas miradas desde la cumbre de un cerro, de los trenes en la lejanía, de grandes playas solitarias azotadas por el viento, cristalizaban en los mejores versos del libro, por aquí y por allá, con precisión, con fantasía, con arrebatada intensidad. Algunos escritores y críticos de la época, entre ellos Pedro Prado, el novelista de Alsino, y Hernán Díaz Arrieta, el hombre que dominaría la crítica chilena durante más de cincuenta años, saludaron de inmediato la aparición de un talento poético de primera magnitud. Todas las personas que contaban para algo en la vida literaria de la época escribieron sobre el poeta que llegaba del sur, y uno de los poemas del libro, "Farewell y los sollozos", se hizo popular de la noche a la mañana.

A comienzos de ese año de la publicación de Crepusculario, en Temuco, durante las vacaciones del verano del hemisferio sur, el poeta había tenido una experiencia literaria 
importante, una experiencia que de alguna manera, a pesar de su fracaso, e incluso a causa de él, resultaría decisiva. El poeta estaba despierto en una ocasión en la casa de su padre, a medianoche. He visitado esa casa hace poco más de veinte años. No sé si todavía existe. Recuerdo una construcción más bien pequeña, de madera, de habitaciones estrechas y oscuras, rodeada por un terreno que hacía las veces de huerto y de jardín. La calle todavía no estaba pavimentada en los tiempos del joven Neruda y debía de convertirse en un barrial la mayor parte del año. En la vereda de enfrente, en toda la esquina, había una bodega y bar, un recinto oscuro, con barricas y sacos en la entrada. Ahí vi llegar a las indias mapuches, con sus trajes típicos y sus adornos de tosca y hermosa platería, cargando sus hijos a la espalda, en busca de sus maridos, que se emborrachaban con chicha de manzana y con los chacolíes y los pipeños de la última cosecha, bebidos en grandes "potrillos" de vidrio verde y opaco. Un poco más allá, al otro lado de una calle más ancha, se encontraba la estación de ferrocarril, la de los trenes longitudinales y la del ramal a la costa, a Nueva Imperial y a Puerto Saavedra. Pensé que ése había sido el centro de operaciones de José del Carmen Reyes, el padre del poeta, obrero ferroviario de profesión, y que Neruda adolescente, esto es, Neruda antes de llamarse y de ser Neruda, se había embarcado ahí en sus excursiones en los trenes lastreros que su padre gobernaba. Eran los trenes encargados de colocar ripio en los durmientes, para que no se los llevara la lluvia, y la tripulación estaba formada por cuchilleros y por ex presidiarios.

Pues bien, en esa noche de enero de 1923, el poeta, antes de acostarse a dormir, abrió las ventanas de su cuarto y se sintió deslumbrado, aturdido, por el cielo recién lavado y cuajado de estrellas. "Corrí a mi mesa", cuenta en sus memorias, Confieso que he vivido, "y escribí de manera delirante, como si recibiera un dictado, el primer poema de un libro que tendría muchos nombres y que finalmente se llamaría El hondero entusiasta.

Como sucede muy a menudo, la fiebre del momento, la insipiración, el entusiasmo, engañaron al "hondero". Leyó el poema a Atiro Oyarzún, conocido en los medios literarios como "el mago", y éste le preguntó de inmediato si no creía que sus versos tenían una influencia directa del uruguayo Sabat Ercasty. Neruda se los envió a Sabat Ercasty y recibió una respuesta elogiosa, pero que confirmaba el reparo de Atiro Oyarzún: "Pocas veces he leído un poema tan logrado, tan magnífico, pero tengo que decírselo: sí hay algo de Sabat Ercasty en sus versos". Fue una decepción profunda, un balde de agua fría, y a la vez "un golpe nocturno, de claridad, que hasta ahora agradezco". Esas decepciones, en los comienzos de la carrera de un escritor, suelen tener una importancia decisiva. Podríamos comparar la de Neruda frente a Oyarzún y a Sabat, dentro de un contexto enteramente diferente, con la decepción del joven Flaubert cuando leyó la primera versión de La tentación de San Antonio a un par de amigos. La reacción negativa de sus auditores llevó a Flaubert a reprimir su retórica, a replegarse, a buscar un tema limitado, provinciano: el adulterio de una señora oscura, casada con un médico de pueblo, y que se llamaría en la ficción Emma Bovary.

En el caso de Neruda, el repliegue, después del torrente verbal de El hombre entusiasta, produjo un libro que todavía sería una etapa en el camino a la madurez, alcanzada algo más tarde con Residencia en la tierra, pero un libro increíblemente popular, que pronto se convertiría en un mito colectivo, sólo comparable, en su condición de mito, a los tangos de Carlos Gardel o a los mejores boleros de las décadas del treinta y del cuarenta: Veinte 
poemas de amor y una canción desesperada. El libro se publicó en 1924, a pesar de la reticencia inicial del editor, Carlos George Nascimento, y tuvo una recepción crítica dividida. Muchos de los admiradores de Crepusculario se sintieron defraudados. Pero hubo poemas como el 15 ("Me gustas cuando callas ...") y como el 20 ("Puedo escribir los versos más tristes ...") que se grabaron de inmediato en la memoria de los lectores. Algunos de esos versos produjeron un efecto irresistible, contagioso, que superó pronto las fronteras chilenas y se extendió a la totalidad del ámbito de la lengua. En sus pensiones miserables del barrio bajo de Santiago, junto a una litografia que representaba al poeta suicida del Romanticismo inglés, Chatterton, y en sus temporadas veraniegas en Temuco y en Puerto Saavedra, el poeta, probablemente sin proponérselo, había escrito un clásico popular. Había suspendido por un tiempo, después de recibir una carta de Sabat Ercasty, su "ambición cíclica de una ancha poesía", había reducido -deliberadamente- su estilo, y había escrito esto otro libro "buscando mis más sencillos rasgos, mi propio mundo armónico".

Neruda contó en diversas oportunidades que Veinte poemas de amor y una canción desesperada pertenece a la atmósfera del sur, de la desembocadura del Bajo Imperial con sus muelles abandonados: "los tablones rotos y los maderos como muñones golpeados por el ancho río, el aleteo de gaviotas [que] se sentía y sigue sintiéndose en aquella desembocadura". Pertenece a ese lugar, pero también a las calles y a los amores estudiantiles de Santiago. Neruda se desplazaba entonces entre la calle Echaurren, la avenida España y los patios y salas del antiguo Instituto Pedagógico, que estaba situado en la Alameda al llegar a la calle Cumming. ¿Cómo serían esos espacios a comienzos de siglo? Hoy día son calles todavía tranquilas, en prolongada decadencia, con árboles frondosos, añosos, y con una arquitectura de casas modestas, de uno o dos pisos, donde asoma de repente, sin embargo, algún torreón gótico victoriano, alguna columna neoclásica, alguna fachada modernista. A través de las palabras del poeta, uno comprende que en los escondites urbanos, en los laberitnos de la ciudad, el poeta encontraba refugios propicios para sus aventuras amorosas y eróticas. El libro es el reflejo, en consecuencia, de dos polos contrapuestos: el de la naturaleza del sur de Chile, con su intensidad salvaje, y el de un Santiago provinciano, sentimental, "con las calles estudiantiles, la universidad y el olor a madreselva del amor compartido".

En sus diversos testimonios, Neruda insiste en la noción del "amor compartido". El movimiento estudiantil del año veinte, escenario de fondo de la escritura de estos poemas, había sido libertario, anarquizante, feminista, vanguardista. Suponemos que el viejo Instituto Pedagógico, donde Neruda frecuentaba mucho más los patios que las salas de clases, era uno de los sitios estratégicos de la efervescencia revolucionaria. También era un punto de encuentro y de liberación erótica. Cuando le preguntaban sobre la inspiradora o las inspiradoras del libro, Neruda siempre esquivaba la respuesta. "No era una sola, eran muchas", me dijo en más de una ocasión. "Una de ellas era la hija del boticario de Puerto Saavedra", me contó en otra oportunidad. Cuando llegué por primera vez a una de las casas del poeta, a comienzos de la década del cincuenta -él todavía estaba casado con Delia del Carril, la Hormiga - una de las inspiradoras estaba sentada en el jardín, callada, observando de reojo, con cierto desgano, las bromas, los devaneos, las risas del grupo de los hombres. Sólo conocí esa relación más tarde, de un modo que se podría llamar retrospectivo, y la verdad es que siempre me costó entenderla. Yo tenía veinte y tantos 
años, y la juventud, desde luego, nunca comprende bien las situaciones donde ha intervenido el paso del tiempo. Neruda, en sus memorias, para resumir y esquivar el asunto de una vez y para siempre, dice que las "dos o tres" que figuran en esos versos "corresponden, digamos, a Marisol y Marisombra". Es importante ese "digamos", que introduce en la frase un elemento distanciador, irónico. Marisol, de acuerdo con el testimonio del poeta, representa la provincia, la naturaleza, la luz solar, y Marisombra corresponde a la penumbra y a los colores grisáceos de Santiago. Marisombra, según Neruda, es la muchacha de la boina gris, pero aquí todo se confunde, puesto que el poema 6 ("Eras la boina gris ..."), según otra afirmación suya, es uno de los dedicados a la naturaleza del sur. Conviene, pues, no esforzarse demasiado por desentrañar estos misterios. Se trata de poesía, no de biografía. Hay muchas inspiradoras, dos o tres, o más, o ninguna precisa, y es posible que en esos años usaran boinas las muchachas de Santiago y las alumnas del Liceo de Niñas de Temuco. Vaya uno a saber.

Hemos repetido los versos de los Veinte poemas durante décadas, primero con asombro, con emoción, con una suerte de compromiso sentimental, y después con humor y con algo de nostalgia, evocando el paisaje mental de nuestra juventud, el de finales de la década del cuarenta y comienzos de los cincuenta. La relectura atenta, metódica, del libro, a cuarenta y más años de distancia de su descubrimiento inicial, no deja de ser interesante. Los dos polos del libro - la capital y la provincia, la naturaleza y la ciudad - representan una dualidad clásica en toda la literatura europea del siglo XIX. También se encuentran en la poesía de algunos españoles de comienzos de siglo, en Antonio y Manuel Machado, en Juan Ramón Jiménez. A pesar de la declarada y conocida enemistad literaria entre ambos, Neruda tenía simpatía por los versos juveniles de Juan Ramón, los versos emotivos y provincianos. Decía que Juan Ramón habia tratado de convertirse más tarde, a la fuerza, en una especie de Paul Valéry español, un autor de poesía más abstracta, más intelectual, y que carecía de condiciones para esto. En cualquier caso, la relación entre el primer Juan Ramón Jiménez y el Neruda de Veinte poemas quizás no sea tan arbitraria como parece a primera vista. Las grandes enemistades, en la literatura, suelen partir de semejanzas, de parentescos iniciales mal tolerados. El Neruda de los Veinte poemas, por ejemplo, leía con pasión a otro rival encarnizado de algunos años más tarde, a Vicente Huidrobo, que se le había adelantado en el camino de la vanguardia. Pero esto ya nos lleva a otra parte, a otros problemas.

La lectura actual de Veinte poemas de amor y una canción desesperada nos revela que es un libro contradictorio, de transición. Por una parte sigue ligado a los ecos tardíos del modernismo. El poeta no ha querido, no ha podido, torcerle el cuello al cisne rubendariano. Precisamente los cisnes, utilizados a la manera de los modernistas, asoman la cabeza en uno que otro verso. "Un cisne, un árbol, algo lejano y alegre ...". Después, en años de poesía madura, tendrá una visión mucho más concreta y dramática: se acordará de los cisnes del lago Budi, exterminados a palos por la barbarie colectiva o por el hambre, y rendirá homenaje a su defensor lírico, Augusto Winter, nuestro primer poeta ecológico, director de la principal biblioteca regional en los años juveniles de Neruda.

La mujer, la inspiradora de estos versos, tiene elementos del simbolismo francés y del modernismo latinoamericano. Buscar modelos reales no sólo es una pérdida de tiempo; es una perfecta ingenuidad. La mujer, las mujeres de esta poesía, sintetizadas con astucia por 
el poeta en Marisol y Marisombra ("digamos"), no son más que una invención literaria. Viven en un escenario inventado y no podrían vivir en ninguna otra parte. La mujer de Veinte poemas está en la distancia, se disuelve en unas colinas lejanas, es de viento, de humo, es el zumbido de una abeja, abeja blanca, para colmo, y siempre se desplaza, emigra hacia un lugar irreal; "hacia donde el crepúsculo corre borrando estatuas". La mujer de los simbolistas, la de algunos poemas de Baudelaire, reaparece después en Residencia en la tierra, en "Ángela Adónica”, por ejemplo, pero ahí ya pertenece a la psicología profunda, a la vanguardia, a los márgenes del surrealismo.

La distancia donde se sitúa el objeto erótico de estos poemas no sólo es espacial. El fantasma femenino está separado de la voz lírica por el espacio y también por el tiempo. Se confirma la teoría, aplicable en forma eminente a la literatura, de que todo tiempo está situado en un espacio, y viceversa. En el célebre poema 6, ese "corazón en calma" pertenece al pasado, a la pasión superada. Por eso el poeta recuerda a la amada "en el último otoño" y utiliza con insistencia el pretérito imperfecto, que evita darle a la memoria una precisión excesiva, que sirve para evocar toda una época, más bien que una acción o un momento concretos:

Más alla de tus ojos ardían los crepúsculos.

Hojas secas de otoño giraban en tu alma.

A pesar de todo esto, el libro anuncia con claridad Residencia en la tierra, que vendrá después del experimento parcialmente fracasado, pero interesante, de Tentativa del hombre infinito. Los gérmenes se notan mejor, a mi juicio, en algunos giros de lenguaje y en los fragmentos menos logrados y menos "pegajosos". En el poema 9 hay prosaísmos que aquí no cristalizaban bien, que no terminan de cuajar, y que más tarde, en el período de las Residencias, serán decisivos: "repentino", "eléctricas gestiones". El verso final de la penúltima estrofa - “y embriagadoras rosas practicándose en mi”- - ya es, por su prosaísmo, por su hermetismo, por el uso del gerundio, enteramente "residenciario". Por lo demás, se sabe que Neruda, en ediciones posteriores, corrigió a fondo el poema 9, lo cual permite suponer que su versión definitiva corresponde a una época más evolucionada.

El poema 17 es anunciador en otro sentido: es un arte poética, género que Neruda cultivaría más tarde en todas las etapas maduras de su poesía. El poeta trabaja "pensando, soltando pájaros, desvaneciendo imágenes". Escribe "ahogando lamentos, moliendo esperanzas sombrías". El poema termina con una pregunta enigmática, reiterada, y sospecho que esa pregunta no va dirigida esta vez, como en la tercera estrofa, a la mujer, sino al poeta mismo: “¿Quién eres tú, quién eres?” Es decir, quién es el poeta, en qué consiste su extraña actividad, que el texto ha intentado describir por medio de metáforas más bien obscuras, de aproximaciones, quién es esta persona que desde la primera línea se encuentra "pensando, enredando sombras en la profunda soledad".

Si se lee el libro en esta forma, "La canción desesperada" parece una despedida en el más completo sentido del término. Es un adiós a esa mujer fantasmagórica, al modernismo, a los muelles, las aguas, las gaviotas melancólicas de la adolescencia. El poeta regresará a ese sitio muchas veces, con la memoria y también en forma física, pero el adolescente enamorado de una mujer de humo, de viento, reiteradamente silenciosa, quedará sepultado 
en el tiempo. Será otro, como ese niño que viaja en un barco y que descubre el mundo, aturdido por el ruido que hacen los mayores, en uno de los poemas de Memorial de Isla Negra, y que ya es "el niño perdido".

Pablo Neruda tenía sentimientos contradictorios con respecto a los Veinte poemas. No le gustaba que lo identificaran con ese libro demasiado célebre y popular. Detestaba que pensaran que su mejor invención era el poema 20: "Puedo escribir los versos más tristes esta noche ...". En sus años finales, en la década del sesenta, estaba obsesionado por la idea de que la gente no leía su nueva producción, de que se contentaba con los versos más conocidos de las etapas anteriores. El poeta escribía con regularidad, con encomiable disciplina, con calidad dispareja, pero con destellos, con chispazos indudables, y la gente compraba sus libros, trataba de obtener un autógrafo, y en seguida los colocaba en un lugar privilegiado de sus estanterías, o en una esa de cristal, cuando se trataba de ediciones de lujo. El poeta coleccionista era víctima del coleccionismo. “¡Nadie me lee!”, solía exclamar, con humor quejumbroso, con un retintín vagamente patético. A veces se citaba a sí mismo, medio en broma, en el momento más bullicioso de una fiesta, o mientras la regocijada compañía bajaba por las escaleras estrechas de La Sebastiana, la casa de Valparaíso, después de haber contemplado desde la terraza el espectáculo de los fuegos artificiales de la noche de Año Nuevo, un ritual que en la década del sesenta se repetía todos los días 31 de diciembre. La falta de reacción de los demás que no reconocían la cita, confirmaba sus sospechas. A la vez, hablaba con satisfacción con algo de ingenuidad, de las parejas que se le acercaban, en Santiago, en el sur de Chile, en plazas de provincia de las ciudades más remotas de América, y le confesaban, agradecidas, que la lectura de los Veinte poemas había dominado en sus primeros encuentros y había contribuido a decidir su destino. El poema 20 había sido como el himno nacional de muchos amores sudamericanos (para emplear una metáfora aplicada por Marcel Proust a la sonata de Vinteuil y a los amores de Swann). El poeta lo sabía y lo hacía saber, pero no le gustaba nada que lo conocieran únicamente como el autor de ese poema.

En el recital que dio en Lima a mediados del año setenta, en una sala enorme y repleta, donde el público se había sentado hasta en los pasillos y en el escenario, a pocos metros de la mesa de lectura, el poeta dejó el indispensable poema 20 para el final, sin anunciarlo, creando un suspenso casi insoportable. ¿Cuándo llegaría el famoso poema? ¿Cometería el poeta la impertinencia, la crueldad, de irse sin haberlo recitado? Cuando leyó el verso archiconocido, tanguero, precursor del "Tango del viudo", hubo una descarga de tensiones, un suspiro limeño inmenso, que sacudió todo el aire del auditorio del colegio de Santa Teresita (o de otra santa con un diminutivo). El poeta no tuvo más remedio que interrumpir y comenzar de nuevo, pero lo hizo con una amplia sonrisa, entre resignado y contento. Leyó en medio de un silencio literalmente religioso, y al final se produjo una ovación atronadora, que estuvo a punto de obligarlo a conceder un "bis", como sucede con los grandes virtuosos. Yo acababa de llegar a Lima, destinado a prestar servicios en la embajada chilena, y tenía un automóvil ínfimo, provisional, un "Austin Mini", que había estacionado en el jardín del colegio de monjas, a un costado de una portezuela que conectaba con el escenario. El poeta y yo salimos a la carrera, para escapar de los frenéticos admiradores del poema 20, de los cazadores y las cazadoras de autógrafos, pero introducir al voluminoso Neruda en el asiento delantero del Mini costó algún trabajo, y los admiradores 
cayeron sobre nosotros en masa, exaltados, desmelenados. Puse el motor en marcha y traté de acelerar, pero los nerudianos habían levantado nuestro ligero vehículo por los aires y las ruedas giraron en banda. De pronto, en un descuido, las ruedas tocaron tierra y nosotros salimos a toda velocidad. Recuerdo que los admiradores más próximos daban saltos agilísimos para no ser atropellados, y que nosotros preferíamos no mirar para atrás.

Neruda se despidió de las nieblas, de los vientos, de los muelles neorrománticos, postmodernistas, de los Veinte poemas, e inició la etapa mejor de su poesía, después del breve ensayo representado por la Tentativa del hombre infinito. Tres años después de la publicación del libro en la editorial Nascimento, irritado con los críticos y satisfecho de su creciente popularidad, partió al Extremo Oriente. Partió, como le gustaba decir, a un "hoyo del globo terráqueo". El Ministro de Relaciones de turno, al ofrecerle un cargo de cónsul de elección, le había mostrado el sitio del globo donde quedaba su destinación, Rangún, en Birmania, y en ese sitio el globo tenía un agujero. En ese lugar irreal, el poeta adquirió distancia, profundidad, sombra. Inventó un lenguaje y escribió algunos de los mejores poemas de este siglo. La poesía de sus veinte años, sin embargo, con su ingenuidad, con su vacilación, con su "olor de madreselvas", con la teatralidad de su "desesperación", sigue siendo interesante. A la vuelta de un poema, de una estrofa, a pesar de la simplicidad de la rima, aparecen versos memorables. "Pura heredera del día destruido", escribe el joven lector de Quevedo. "Muñeca triste y dulce", dice el admirador de Gardel y de Amado Nervo, el que después afirmaría con arrogancia en un texto de Madrid, Sobre una poesía sin pureza: "quien huye del mal gusto cae en el hielo". El vanguardista sudamericano, el conocedor de Borges, de Oliverio Girondo, de Huidobro, de Ramón López Velarde, habla de ese lugar ficticio, metafísico, "hacia donde el crepúsculo corre borrando estatuas". Nosotros leemos con una sonrisa. Ya los Veinte poemas de amor y una canción desesperada son historia, y tienen el sabor mejor de la historia. Las parejas de ahora, que se forman al son de una cantante de rock o de cosas peores, podrán escoger el libro como curiosidad, como cosa del tiempo de sus abuelos. Pero hay que tener cuidado: los versos conservan, a pesar de todo, su magia secreta, contagiosa y peligrosa. 
